\title{
Timeliness of postnatal surgery in newborns with open neural tube defects: a single center experience
}

\author{
Ayhan Pektaş ${ }^{1 \oplus}$, Mehmet Gazi Boyaci ${ }^{2 \oplus}$, Hilal Koyuncu ${ }^{3 \oplus}$, Mine Kanat Pektaş ${ }^{4}$, \\ Ahmet Afşin Kundak ${ }^{50}$ \\ Departments of ${ }^{1}$ Pediatric Cardiology, ${ }^{2}$ Neurosurgery, ${ }^{3}$ Pediatrics, ${ }^{4}$ ObstetricsEGynecology, and ${ }^{5}$ Neonatology, Afyonkarahisar Health \\ Sciences University Faculty of Medicine, Afyonkarahisar, Turkey.
}

\begin{abstract}
Background. This study aims to evaluate the experience of a tertiary health center on the timeliness of postnatal management in newborns with open neural tube defects (NTDs).

Methods. This is a retrospective review of 38 neonates with NTDs who were treated surgically at a tertiary health care center between January 2009 and January 2019. Five neonates with genetic syndromes were excluded.

Results. Twenty-six neonates with NTD underwent surgery on the first postnatal day while 12 neonates with NTD had surgery after the first postnatal day. The reasons for the latency in operative treatment were the delay in the referral of the affected newborn from other health care centers $(n=8)$ and the transient abnormalities in coagulation tests $(n=4)$.

Rural residence was significantly more frequent, gestational age at delivery was significantly lower, preterm delivery was significantly more frequent and prenatal diagnosis was significantly less frequent in neonates that underwent surgery for NTD repair after the first postnatal day $(\mathrm{p}=0.001, \mathrm{p}=0.048, \mathrm{p}=0.024$ and $\mathrm{p}=0.003$ respectively). Postoperative motor dysfunction was significantly more severe $(p=0.002)$, postoperative complications were significantly more frequent $(\mathrm{p}=0.008)$, the reoperation and postoperative mortality rates were significantly higher ( $\mathrm{p}=0.009$ and $\mathrm{p}=0.048$ respectively) and the duration of hospital stay was significantly longer $(\mathrm{p}=0.033)$ for the neonates who underwent surgery after the first postnatal day.
\end{abstract}

Conclusions. Our study appears to favor the early repair of NTD's within the first 24 hours of life. Such an approach may reduce the risk of infectious and neurological complications significantly.

Key words: morbidity, mortality, neural tube defects, operative surgical procedures.

Neural tube defects (NTDs) are the second most common birth defects of the whole system and the most common congenital anomaly of the central nervous system. These defects emerge when part of the neural tube fails to close normally during the third to the fourth week after conception. ${ }^{1,2}$

Most of the isolated NTDs are caused by folate deficiency, likely in combination with genetic or other environmental risk factors consisting

$\triangle$ Ayhan Pektaş

drayhanpektas@hotmail.com

Received 7th August 2020, revised 11th December 2020, accepted 31st December 2020. of fever/hyperthermia, obesity, pregestational diabetes, exposure to pesticides, nitrosatable drugs and clomiphene citrate. ${ }^{3,4}$ These defects may be associated with syndromes such as Edwards', Patau, Meckel-Gruber, Roberts, Jarcho-Levin as well as triploidy, limb-body wall complex, and cloacal exstrophy. ${ }^{5,6}$

The improvements in diagnostic equipment and therapeutic procedures have caused a dramatic increase in survival and life expectancy rates of the individuals affected by NTDs. ${ }^{78}$ Despite this fact, the risk of morbidity and mortality still remains significantly increased for newborns diagnosed with these congenital defects. ${ }^{8,9}$ It has been hypothesized that morbidity and 
mortality associated with the management of NTDs is more pronounced in developing and underdeveloped countries with limited resources and access to health care. ${ }^{9,10}$

Approximately $80 \%$ of NTDs are open lesions such as myelomeningocele (spina bifida), meningocele, encephalocele, and anencephaly. ${ }^{11}$ These lesions can be associated with cerebral ventriculomegaly. ${ }^{12}$ The standard of treatment for open NTDs is the prenatal surgical repair or postnatal repair within the first few days of life. ${ }^{13}$ The rationale behind the recommendation of prompt postnatal closure is to prevent infectious complications and protect the exposed nerves from possible trauma. ${ }^{12,13}$

This study aims to evaluate the experience of a tertiary health center on the timeliness of postnatal management in newborns with open NTDs.

\section{Material and Methods}

The present study was approved by the Institutional Review Board and Ethical Committee of Afyonkarahisar Health Sciences University (02.08.2019-261).

This was a retrospective review of 43 neonates with NTDs who were treated surgically at a tertiary health care center between January 2009 and January 2019. The parents of these neonates were counseled for the management of NTDs and they were provided with written informed consent for surgical treatment.

Data related with prenatal diagnosis, gestational age at the time of delivery, birth weight, birth length, sex, mode of delivery, and Apgar scores were obtained from the medical records.

Data concerning family history, maternal age, maternal residence, maternal smoking and use of anti-epileptic drugs were also derived from the hospital files. In addition, the type and localization of NTDs, co-existing congenital anomalies, timing and type of surgery were designated. The duration of hospital stay, findings of neurological imaging, postoperative complications, postoperative mortality and the reasons for re-operation were also specified.

\section{Statistical analysis}

Collected data were analyzed with Statistical Package for Social Sciences version 22.0 (SPSS IBM, Armonk, NY, USA). Continuous variables were expressed as mean \pm standard deviation (range: minimum-maximum) whereas categorical variables were denoted as numbers or percentages. Mann Whitney U test was used to compare the continuous variables and chi square test was utilized to compare the categorical variables. Two-tailed $p$ values less than 0.05 were accepted to be statistically significant.

\section{Results}

Twenty-six neonates with NTD underwent surgery on the first postnatal day $(68.4 \%)$ while 10 neonates with NTD had surgery on the second postnatal day (26.3\%) and 2 neonates with NTD had surgical repair on the third postnatal day $(5.3 \%)$. The reasons for the latency in operative treatment were the delay in the referral of the affected newborns from primary and secondary health care centers $(n=8)$ and the transient abnormalities in coagulation tests $(n=4)$.

Two neonates who also had Meckel Gruber syndrome, one neonate who was also diagnosed with Edwards' syndrome, one neonate who also had Patau syndrome and one neonate who was also diagnosed with Roberts' syndrome were excluded from the study.

Table I compares the sociodemographic characteristics of the neonates with NTDs with respect to the timing of surgery. Rural residence was significantly more frequent, gestational age at delivery was significantly lower and preterm delivery was significantly more frequent in neonates that underwent surgery for NTD repair after the first postnatal day $(\mathrm{p}=0.001$, $\mathrm{p}=0.048$ and $\mathrm{p}=0.024$ respectively). Maternal age and smoking, maternal use of anti-epileptic 
Table I. Sociodemographic characteristics of the neonates with neural tube defects.

\begin{tabular}{lccc}
\hline & $\begin{array}{c}\text { Surgery at first } \\
\text { postnatal day } \\
(\mathrm{n}=26)\end{array}$ & $\begin{array}{c}\text { Surgery after first } \\
\text { postnatal day } \\
(\mathrm{n}=12)\end{array}$ & $\mathrm{p}$ \\
\hline Maternal age (years) & $34.6 \pm 4.7$ & $33.8 \pm 5.6$ & 0.554 \\
Maternal residence (Urban/Rural) & $21(80.8 \%) / 5(19.2 \%)$ & $2(16.7 \%) / 10(83.3 \%)$ & $0.001^{*}$ \\
Maternal smoking & $2(7.7 \%)$ & $0(0.0 \%)$ & 0.324 \\
Maternal use of anti-epileptic drugs & $1(3.8 \%)$ & $0(0.0 \%)$ & 0.491 \\
Positive family history & $2(7.7 \%)$ & $0(0.0 \%)$ & 0.324 \\
Gestational age at the time of delivery (weeks) & $39.3 \pm 2.5$ & $36.2 \pm 3.8$ & $0.048^{*}$ \\
Preterm delivery (<37 weeks) & $4(15.4 \%)$ & $6(50.0 \%)$ & $0.005^{*}$ \\
Birth weight (grams) & $3012.7 \pm 154.8$ & $2715.5 \pm 127.8$ & 0.117 \\
Birth length (cm) & $50.4 \pm 4.1$ & $49.3 \pm 5.4$ & 0.514 \\
Head circumference (cm) & $42.3 \pm 2.9$ & $39.2 \pm 3.7$ & 0.492 \\
Male / Female & $13(50.0 \%) / 13(50.0 \%)$ & $4(33.3 \%) / 8(66.7 \%)$ & 0.337 \\
Vaginal / Cesarean delivery & $2(7.7 \%) / 24(92.3 \%)$ & $1(8.3 \%) / 11(91.7 \%)$ & 0.946 \\
1st minute Apgar score & $7.2 \pm 1.9$ & $7.3 \pm 2.8$ & 0.911 \\
5th minute Apgar score & $8.8 \pm 3.1$ & $8.4 \pm 3.5$ & 0.876 \\
\hline
\end{tabular}

${ }^{*} \mathrm{p}<0.05$ was accepted to be statistically significant.

drugs, positive family history, birth weight, birth length, head circumference, sex, mode of delivery and Apgar scores were statistically similar in both groups of neonates ( $p>0.05$ for each).

Table II compares the clinical characteristics of the affected neonates based on the timing of postnatal surgery. Prenatal diagnosis was significantly more frequent in the neonates who underwent NTD surgery on the first postnatal day $(p=0.003)$. The neonates who had NTD repair on the first postnatal day and the neonates who had surgery after the first postnatal day were statistically similar in regards to gestational age at prenatal diagnosis, NTD type and localization, coexisting congenital anomalies and imaging findings ( $p>0.05$ for each).

Table III compares the clinical outcomes of the neonates with NTDs depending on the timing of the surgery. Postoperative motor dysfunction was significantly more severe $(\mathrm{p}=0.002)$, postoperative complications were significantly more frequent $(\mathrm{p}=0.008)$, the reoperation and postoperative mortality rates were significantly higher ( $\mathrm{p}=0.009$ and $\mathrm{p}=0.048$ respectively) and the duration of hospital stay was significantly longer $(p=0.033)$ for the neonates who underwent surgery after the first postnatal day than the neonates who had surgery on the first postnatal day (Fig. 1).

\section{Discussion}

The morbidity and mortality related to NTDs in newborns vary worldwide. This variation has been attributed to age, sex, ethnicity, level and severity of the lesion, co-existence of multiple birth defects as well as availability and use of treatment modalities. ${ }^{8-10}$ It has been reported that the survival and well-being of the neonates born with NTDs are negatively affected by low birth weight and lesions located at relatively higher levels of the spinal cord. ${ }^{14,15}$ Another poor prognostic factor for newborns with NTDs has been addressed as concurrence of NTDs with other congenital abnormalities, chromosomal aberrations and genetic syndromes. ${ }^{14,16}$ The major reason for this observation is that isolated cases of NTD tend to be less complicated. ${ }^{16}$ On the other hand, it has been shown that early intervention after birth enhances the survival 
Table II. Clinical characteristics of the neonates with neural tube defects.

\begin{tabular}{|c|c|c|c|}
\hline & $\begin{array}{l}\text { Surgery on the first } \\
\text { postnatal day } \\
\qquad(n=26)\end{array}$ & $\begin{array}{l}\text { Surgery after the first } \\
\text { postnatal day } \\
\qquad(\mathrm{n}=12)\end{array}$ & $\mathrm{p}$ \\
\hline Prenatal diagnosis & $24(92.3 \%)$ & $6(50.0 \%)$ & $0.003^{*}$ \\
\hline Gestational age at prenatal diagnosis & $18.6 \pm 2.4$ & $19.3 \pm 1.7$ & 0.266 \\
\hline Type of neural tube defect & & & 0.213 \\
\hline Myelocele & $0(0.0 \%)$ & $1(8.3 \%)$ & \\
\hline Encephalocele & $2(7.7 \%)$ & $0(0.0 \%)$ & \\
\hline Meningomyelocele & $24(92.3 \%)$ & $11(91.7 \%)$ & \\
\hline Localization of neural tube defect & & & 0.784 \\
\hline Lumbosacral & $11(42.3 \%)$ & $5(41.7 \%)$ & \\
\hline Thoracolumbar & $8(30.8 \%)$ & $4(33.3 \%)$ & \\
\hline Thoracolumbosacral & $5(19.2 \%)$ & $3(25.0 \%)$ & \\
\hline Lumbar & $2(7.7 \%)$ & $0(0.0 \%)$ & \\
\hline Co-existing congenital anomalies & & & 0.526 \\
\hline Hydrocephaly & $14(53.8 \%)$ & $6(50.0 \%)$ & \\
\hline Pes equinovarus & $7(27.0 \%)$ & $3(25.0 \%)$ & \\
\hline Congenital cardiac disease & $5(19.2 \%)$ & $2(16.7 \%)$ & \\
\hline Hydronephrosis & $0(0.0 \%)$ & $1(8.3 \%)$ & \\
\hline Neurological imaging findings & & & 0.761 \\
\hline Hydrocephaly & $15(57.7 \%)$ & $5(41.6 \%)$ & \\
\hline Colpocephaly & $5(19.2 \%)$ & $3(25.0 \%)$ & \\
\hline Arnold-Chiari malformation & $4(15.4 \%)$ & $2(16.7 \%)$ & \\
\hline Agenesis of corpus callosum & $2(7.7 \%)$ & $2(16.7 \%)$ & \\
\hline
\end{tabular}

and well being of the neonates diagnosed with NTDs. ${ }^{14,15}$

The timing of surgery for postnatal treatment of NTD remains a controversial topic in the literature. It has been hypothesized that surgical repair of NTD within the first two days of life prevents further impairment in motor functions, contributes to the well being of the genitourinary system and decreases the risk of infectious complications. ${ }^{17,18}$ A retrospective review of 401 children with myelomeningocele reported significantly higher incidences of febrile urinary tract infections, vesicoureteral reflux and hydronephrosis for the patients who underwent primary neurosurgical repair after 72 hours following delivery. ${ }^{17}$ Pinto et al. ${ }^{13}$ claimed that surgical repair carried out immediately after delivery (at time zero) was associated with significantly lower incidence of preoperative myelomeningocele rupture, postoperative dehiscence and neurodevelopmental delay during the first year of life. Oncel et al. ${ }^{18}$ also supported the early surgical intervention in NTD patients as surgery within the first five days of postnatal life came up with significantly shorter hospital stay and antibiotic therapy duration as well as significantly lower complication rate. A retrospective cohort study conducted in 70 patients with meningomyelocele showed that surgical repair performed after 48 hours of life increased the risk of central nervous system infections 5.72 times. $^{19}$

However, an analysis of a nationwide database failed to find any significant difference in rates of infection between same-day and 1-day waiting for NTD surgery. It has been found that the prolongation of two or more days in surgery time led to an increase of infection rates 
Table III. Clinical outcomes with respect to timing of surgery.

\begin{tabular}{lccc}
\hline & $\begin{array}{c}\text { Surgery on the first } \\
\text { postnatal day } \\
(\mathrm{n}=26)\end{array}$ & $\begin{array}{c}\text { Surgery after the first } \\
\text { postnatal day } \\
(\mathrm{n}=12)\end{array}$ & $\mathrm{p}$ \\
\hline Type of surgery & $6(23.1 \%)$ & $4(33.3 \%)$ & 0.505 \\
$\quad$ NTD repair & $20(76.9 \%)$ & $8(66.7 \%)$ & $0.002^{*}$ \\
NTD repair \& Ventriculoperitoneal shunt & $6(23.1 \%)$ & $6(50.0 \%)$ & \\
Postoperative motor dysfunction & $2(7.7 \%)$ & $4(33.3 \%)$ & \\
$\quad$ Complete loss above L4 & $1(3.8 \%)$ & $2(16.7 \%)$ & $0.008^{*}$ \\
Partial loss above L4 & $4(15.4 \%)$ & $4(33.3 \%)$ & \\
Partial loss at L4 and below & $3(11.5 \%)$ & $3(25.0 \%)$ & \\
Postoperative complications & $1(3.8 \%)$ & $3(25.0 \%)$ & \\
$\quad$ CSF leakage & $0(0.0 \%)$ & $2(16.7 \%)$ & \\
Wound infection & & & \\
CSF leakage \& Wound infection & $5(19.2 \%)$ & $5(41.7 \%)$ & \\
Meningitis & $3(11.5 \%)$ & $3(25.0 \%)$ & \\
Re-operation & $1(3.8 \%)$ & $3(25.0 \%)$ & $0.048^{*} 0.033^{*}$ \\
Wound infection & $1(3.8 \%)$ & $3(25.0 \%)$ & \\
CSF leakage & $43.7 \pm 11.6$ & $78.6 \pm 19.9$ & \\
Recurring hydrocephaly & & & \\
Postoperative mortality & & & \\
Duration of hospital stay & & & \\
\hline
\end{tabular}

NTD: Neural tube defect, CSF: Cerebrospinal fluid

${ }^{*} \mathrm{p}<0.05$ was accepted to be statistically significant.

by $65 \%$ and $88 \%$, respectively. The presence of infection was associated with a $54 \%$ increase in the duration of hospital stay. Thus, the delay of NTD closure for more than 1 day after birth was found to correlate with a significant rise in infection and hospitalization rates. ${ }^{20}$

Radcliff et al. ${ }^{21}$ held out a retrospective, statewide and population-based study for infants born in Florida between 1998 and 2007 and examined the neonates born with spina bifida as confirmed by the Florida Birth Defects Registry. They determined that the affected newborns that were delivered at primary and secondary health care centers were less likely to undergo surgery on the first postnatal day. It has been suggested that the lower prevalence of timely surgical repair in newborns with spina bifida might be due to the lack of prenatal diagnosis and related lack of appropriate referral to a tertiary health care center.
Complying with the literature, this study indicated a significantly less frequency of prenatal diagnosis in newborns that had surgery after the first postnatal day. Moreover, the reason for the latency in surgical repair was the delay in the referral from primary and secondary health care centers for 8 newborns. The lack of prenatal diagnosis for NTD might prevent the in utero referral of affected fetuses for delivery in tertiary health care centers and result in the birth of affected fetuses in primary and secondary health care centers. This might cause prolongation in the time needed for a transfer to a hospital with a higher level of health care.

Radcliff et al. ${ }^{21}$ also concluded that preterm infants born with spina bifida were more likely to have delayed surgical repair than term infants. Similarly, in this study, the frequency of preterm delivery was significantly higher in newborns that had delayed surgery. 


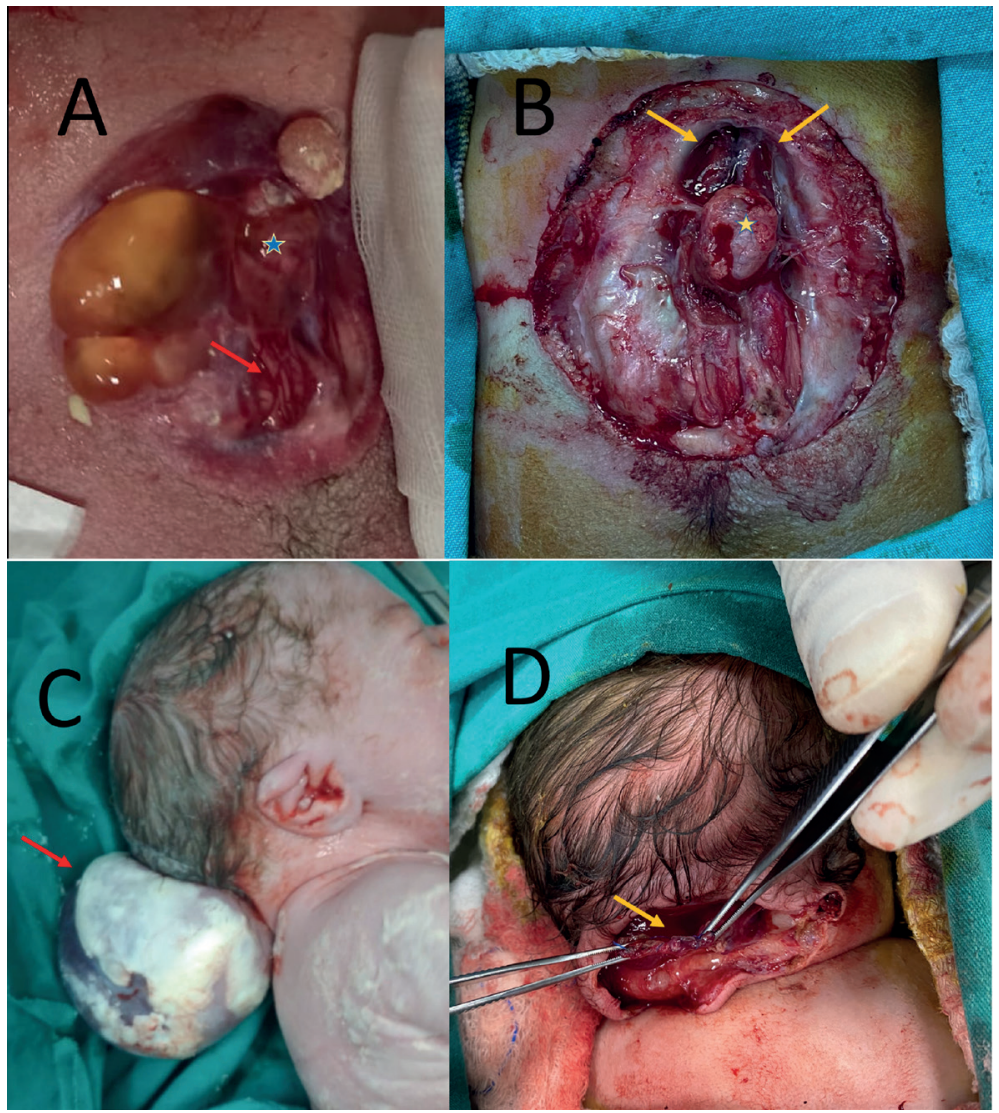

Fig. 1. (a) Meningomyelocele and diasthometamyelia can occur concurrently, (b) When the myelomeningocele sac is excised, the spinal cord split by a bone fragment becomes more obvious, (c) Encephalocele sac is marked with an arrow, (d) After the excision of encephalocele sac, the dura mater is sutured.

On the contrary, Radcliff et al. ${ }^{21}$ failed to detect any differences in the timing of spina bifida surgery by type of the lesion. They also speculated that the simultaneous existence of other medical conditions may not be an underlying cause for the latency in the surgical treatment of spina bifida. As for the present study, the neonates who had surgery on the first postnatal day and the neonates who had surgery after the first postnatal day were statistically similar in respect to the NTD type. In order to avoid bias related to coexisting medical conditions, all newborns diagnosed with concurrent NTD and genetic syndromes were excluded from this study.
In this study, postoperative motor dysfunction was significantly more severe, postoperative complications were significantly more frequent and the duration of hospital stay was significantly longer for the neonates who underwent surgery after the first postnatal day than the neonates who had surgery on the first postnatal day. Our study appears to favor the early repair of NTD within the first 24 hours of life. Such an approach may reduce the risk of infectious and neurological complications significantly and allow the pediatric neurosurgeons to use the pregnancy as a period of time for comprehensive counseling of the parents who need to give consent for the surgical treatment of their newborns. 
The findings of the present study should be interpreted carefully as its power is limited by the retrospective study design, small sample size and lack of data about ventriculoperitoneal shunt infections. Further research is warranted to clarify the long-term consequences of early postnatal management in newborns with NTD.

\section{Author contribution}

The authors confirm contribution to the paper as follows: study conception and design: AP, AAK; data collection: HK, MGB; analysis and interpretation of results: $\mathrm{AP}, \mathrm{MKP}, \mathrm{AAK}$; draft manuscript preparation: AP, MGB, MKP. All authors reviewed the results and approved the final version of the manuscript.

\section{Ethical approval}

The present study was approved by the Institutional Review Board and Ethical Committee of Afyonkarahisar Health Sciences University (02.08.2019-261).

\section{Source of funding}

We declare that there is no financial assistance in our work.

\section{Conflict of interest}

The authors declare no conflict of interest.

\section{REFERENCES}

1. Greene ND, Copp AJ. Neural tube defects. Annu Rev Neurosci 2014; 37: 221-242.

2. Aygün C, Kurucu S, Çakmak-Çelik F, Dağçınar A, Tanyeri B, Küçüködük Ş. Experience of a tertiary care center on 100 newborns with neural tube defects. Turk J Pediatr 2013; 55: 359-364.

3. Padmanabhan R. Etiology, pathogenesis and prevention of neural tube defects. Congenit Anom (Kyoto) 2006; 46: 55-67.
4. Kondo A, Matsuo T, Morota N, Kondo AS, Okai I, Fukuda H. Neural tube defects: risk factors and preventive measures. Congenit Anom (Kyoto) 2017; 57: 150-156.

5. Nazki FH, Sameer AS, GanaieBA. Folate: metabolism, genes, polymorphisms and the associated diseases. Gene 2014; 533: 11-20.

6. Toru HS, Sanhal CY, Uzun ÖC, Ocak GA, Mendilcioğlu İ, Karaveli FŞ. Associated anomalies with neural tube defects in fetal autopsies. J Matern Fetal Neonatal Med 2016; 29: 798-802.

7. Oakeshott P, Hunt GM, Poulton A, Reid F. Expectation of life and unexpected death in open spina bifida: a 40-year complete, non-selective, longitudinal cohort study. Dev Med Child Neurol 2010; 52: 749-753.

8. Wang Y, Hu J, Druschel CM, Kirby RS. Twenty-fiveyear survival of children with birth defects in New York State: a population-based study. Birth Defects Res A Clin Mol Teratol 2011; 91: 995-1003.

9. Shin M, Kucik JE, Siffel C, et al. Improved survival among children with spina bifida in the United States. J Pediatr 2012; 161: 1132-1137.

10. Kancherla V, Druschel CM, Oakley GP Jr. Populationbased study to determine mortality in spina bifida: New York State Congenital Malformations Registry, 1983 to 2006. Birth Defects Res A Clin Mol Teratol 2014; 100: 563-575.

11. Zaganjor I, Sekkarie A, Tsang BL, et al. Describing the prevalence of neural tube defects worldwide: a systematic literature review. PLoS ONE 2016; 11: e0151586.

12. Copp AJ, Greene ND. Genetics and development of neural tube defects. J Pathol 2010; 220: 217-230.

13. Pinto FC, Matushita H, Furlan AL, et al. Surgical treatment of myelomeningocele carried out at 'time zero' immediately after birth. Pediatr Neurosurg 2009; 45: 114-118.

14. Bakker MK, Kancherla V, Canfield MA, et al Analysis of mortality among neonates and children with spina bifida: an International Registry-Based Study, 2001-2012. Paediatr Perinat Epidemiol 2019; 33: $436-448$

15. Kancherla V, Ma C, Grant G, Lee HC, Hintz SR, Carmichael SL. Factors associated with early neonatal and first-year mortality in infants with myelomeningocele in California from 2006 to 2011. Am J Perinatol 2020. doi: 10.1055/s-0040-1712165. 
16. Glinianaia SV, Morris JK, Best KE, et al. Long-term survival of children born with congenital anomalies: a systematic review and meta-analysis of populationbased studies. PLoS Med 2020; 17: e1003356.

17. Tarcan T, Önol FF, İlker Y, Alpay H, Şimşek F, Özek M. The timing of primary neurosurgical repair significantly affects neurogenic bladder prognosis in children with myelomeningocele. J Urol 2006; 176: 1161-1165.

18. Oncel MY, Ozdemir R, Kahilogulları G, Yurttutan S, Erdeve O, Dilmen U. The effect of surgery time on prognosis in newborns with meningomyelocele. J Korean Neurosurg Soc 2012; 51: 359-362.
19. Rodrigues ABD, Krebs VLJ, Matushita H, de Carvalho WB. Short-term prognostic factors in myelomeningocele patients. Childs Nerv Syst 2016; 32: $675-680$.

20. Attenello FJ, Tuchman A, Christian EA, et al. Infection rate correlated with time to repair of open neural tube defects (myelomeningoceles): an institutional and national study. Childs Nerv Syst 2016; 32: 1675-1681.

21. Radcliff E, Cassell $\mathrm{CH}$, Laditka SB, et al. Factors associated with the timeliness of postnatal surgical repair of spina bifida. Childs Nerv Syst 2016; 32: 1479-1487. 